\title{
Rapid diagnostic testing of toxigenic microfungi isolated from foodstuffs
}

\author{
Marie Jefremova ${ }^{1}$, Vladimír Ostrý ${ }^{1}$, František Malíř ${ }^{2}$, Jiří Ruprich ${ }^{1}$ \\ ${ }^{1}$ National Institute of Public Health in Prague, Centre for Health, Nutrition, and Food, Brno, Czech Republic \\ ${ }^{2}$ University of Hradec Králové, Faculty of Science, Department of Biology, Hradec Králové, Czech Republic \\ Received August 28, 2015 \\ Accepted May 2, 2016
}

\begin{abstract}
The aim of this study was to experimentally test chromogenic media and reagents for a rapid diagnosis of toxigenic microfungi Aspergillus flavus, A. carbonarius, A. ochraceus, Penicillium expansum, $P$. verrucosum, and $P$. citrinum isolated from foodstuffs. Toxigenic microfungi of Aspergillus and Penicillium species are considered to be of major relevance for human and animal health. The presence of these toxigenic microfungi in foodstuffs and feedstuffs raises a potential risk of mycotoxins (for example presence of aflatoxins, cyclopiazonic acid, ochratoxin A, patulin or citrinin). In order to reduce the risks for consumers' health, it is necessary to set rapid methods for toxigenic microfungi isolated from foodstuffs and also feedstuffs. Application of chromogenic media and reagents presents one of the possibilities. The selected strains of toxigenic microfungi, producing mycotoxins, were tested on chromogenic media. The chromogenic media and reagents in our study are suitable for a microbiological and mycological laboratory. The benefits of chromogenic media and reagents include a rapid diagnosis within 48-72 h, simple preparation, easy availability and relatively low prices.
\end{abstract}

Toxigenic microfungi, mycotoxins, chromogenic media, reagents, food and feed safety

Due to their enzymatic equipment, toxigenic microfungi may easily contaminate almost any substrate. Their huge morphological diversity and their ability to adapt to various environmental conditions allow them to colonize a number of different biotopes, including the household environment - especially kitchens, pantries, and subsequently, foodstuffs. In terms of human and animal health, foodstuffs and feedstuffs are a very suitable substrate for the settlement, growth and reproduction of toxigenic microfungi and for subsequent mycotoxin production (Pitt 2000). The presence of toxigenic microfungi of Aspergillus (Varga et al. 2003) and Penicillium (Pitt 2002) species (e.g. Aspergillus flavus, A. carbonarius, A. ochraceus, Penicillium verrucosum, $P$. expansum, and $P$. citrinum) in foodstuffs and feedstuffs raises a potential risk of production of mycotoxins (e.g. aflatoxins, cyclopiazonic acid, ochratoxin A and citrinin) that have a major impact on human and animal health (Pitt 2000; Ramírez-Camejo et al. 2012; Ostry 2013). In particular, aflatoxins are among the most important mycotoxins that contaminate food and feed ingredients (Klich 2007; Wu 2015).

Rapid diagnostic methods are, therefore, necessary for toxigenic microfungi isolated from foodstuffs in order to reduce the risks for consumers' health. Chromogenic media present one of the possibilities. These chromogenic media are also easy to prepare for rapid determination of microfungi and detection of mycotoxins, and they are less expensive than the other methods tested. At our institute, the study MYCOMON was realized, which revealed the need for a rapid diagnosis of toxigenic microfungi Aspergillus section Flavi isolated from foodstuffs.

This study is focused on the identification and testing of culture media and reagents for a rapid diagnosis of toxigenic microfungi of Aspergillus and Penicillium species isolated from foodstuffs. It is expected that these chromogenic media will be used as screening tests in laboratories with the basic equipment for mycological and microbiological diagnosis.

Address for correspondence:

Mgr. Marie Jefremova

National Institute of Public Health in Prague

Center for Health, Nutrition and Food

Palackého 3A, 61242 Brno, Czech Republic
Phone: +420515577524

Fax: +420541212953

E-mail: jefremova@chpr.szu.cz

http://actavet.vfu.cz/ 


\section{Materials and Methods}

Toxigenic microfungi strains

For experimental purposes toxigenic microfungi of Aspergillus and Penicillium species were used from four collections. Strains of toxigenic microfungi (positive controls on the mycotoxin production) were tested on chromogenic media in duplicates. The strains are shown in Table 1.

Table 1. The strains of toxigenic microfungi (positive controls).

\begin{tabular}{lccll}
\hline Name & Source & Indication & Mycotoxin & Foodstuff \\
\hline Aspergillus flavus & $\mathrm{CCF}{ }^{\mathrm{a}}$ & 139 & $\begin{array}{l}\text { Aflatoxin } \mathrm{B}_{1}, \\
\text { cyclopiazonic acid }\end{array}$ & Unknown \\
Aspergillus flavus & $\mathrm{NRC}^{\mathrm{b}}$ & $\mathrm{M}-63-11$ & Aflatoxin $\mathrm{B}_{1}$ & Fruit tea \\
Aspergillus carbonarius & $\mathrm{ITEM}^{\mathrm{c}}$ & 5010 & Ochratoxin A & Wine grapes \\
Aspergillus ochraceus & $\mathrm{CCM}^{\mathrm{d}}$ & $\mathrm{F}-269$ & Ochratoxin A, B & Maize \\
Penicillium citrinum & $\mathrm{CCF}^{\mathrm{a}}$ & 1812 & Citrinin & Pulverized ice-cream \\
Penicillium expansum & $\mathrm{NRC}^{\mathrm{b}}$ & $\mathrm{P}-27 / 2-14$ & Patulin & Wine grapes \\
Penicillium verrucosum & $\mathrm{CCF}^{\mathrm{a}}$ & 1636 & Ochratoxin A, citrinin & Seeds of barley \\
\hline
\end{tabular}

${ }^{a}$ The Culture Collection of Fungi (Department of Botany, Faculty of Science, Charles University in Prague)

${ }^{\mathrm{b}}$ The collection of the National Reference Centre for microscopic fungi and their mycotoxins in food chains (the National Institute of Public Health in Prague, Center of Health, Nutrition and Food in Brno)

${ }^{c}$ The collection of the Institute of Sciences of Food Production (the National Research Council in Italy)

d The Czech Collection of Microorganisms (Masaryk University in Brno)

\section{Culture media}

In this study, culture media were used for the pre-preparation of the toxigenic strains on diagnostics by chromogenic media. They were chosen based on culture media for selected toxigenic strains (Table 2). As a middle step semisolid agar was used for inoculation of selected toxigenic strains on the chromogenic media. Semisolid agar was prepared by adding $0.2 \%$ bacteriological agar and $0.05 \%$ Tween 80 into the $100 \mathrm{ml}$ of sterile water. Then, semisolid agar was sterilized by autoclaving at $121^{\circ} \mathrm{C}$ for $15 \mathrm{~min}$.

Table 2. The culture media for selected toxigenic strains.

\begin{tabular}{llc}
\hline Culture medium & \multicolumn{1}{c}{ Toxigenic strain } & Incubation \\
\hline MEA $^{\mathrm{a}}$ & Aspergillus ochraceus CCM F-269 & $25^{\circ} \mathrm{C} / 7$ days \\
PDA $^{\mathrm{b}}$ & Aspergillus flavus NRC M-63-11 & $30^{\circ} \mathrm{C} / 4$ days \\
YES $^{\mathrm{c}}$ & Aspergillus flavus NRC M-63-11 & $30^{\circ} \mathrm{C} / 3$ days \\
& Aspergillus flavus NRC M-63-11 & $30^{\circ} \mathrm{C} / 7$ days \\
& Aspergillus flavus CCF 139 & $25^{\circ} \mathrm{C} / 7$ days \\
\hline
\end{tabular}

a Malt Extract Agar

b Potato Dextrose Agar

c Yeast Extract Sucrose agar

Chromogenic media

For the purposes of this study, the following chromogenic media were used for a rapid diagnosis of toxigenic microfungi Aspergillus and Penicillium species. To all chromogenic media a certain volume of distilled water was added and mixed well. The bottle with suspension was heated until agar dissolved and then sterilized by autoclaving at $121{ }^{\circ} \mathrm{C}$ for $15 \mathrm{~min}$. Next, the media were equilibrated in a water bath at $48{ }^{\circ} \mathrm{C}$.

\section{Aspergillus Differentiation Medium Base (ADMB)}

Up to the $22.75 \mathrm{~g}$ of ADMB agar (supplied by HiMedia, India) were added to $500 \mathrm{ml}$ of distilled water. After autoclaving one vial of Chloramphenicol Selective Supplement (SR0078E, supplied by Oxoid, England) 
reconstituted by instruction was added. The prepared medium was poured into sterile Petri dishes. After solidification of the ADMB on the dishes, the toxigenic strain of A. flavus CCF 139 was inoculated and incubated at $30^{\circ} \mathrm{C}$ after $2-3$ days.

\section{Aspergillus flavus and parasiticus Agar (AFPA)}

The amount of $22.75 \mathrm{~g}$ of AFPA (supplied by Oxoid, England) was added to $500 \mathrm{ml}$ of distilled water. After autoclaving one vial of Chloramphenicol Selective Supplement (SR0078E, supplied by Oxoid, England) reconstituted as directed was added. The medium was poured into the sterile Petri dishes. On the agar, the toxigenic strain of $A$. flavus CCF 139 was inoculated and incubated at $30^{\circ} \mathrm{C}$ for 2 days.

\section{Ammonium Hydroxide Test (AHT)}

The selected strain of $A$. flavus NRC M-63-11 was cultivated on the YES agar at $30{ }^{\circ} \mathrm{C}$ for 3 days. Then, glass Petri dish was turned upside down and on the lid $200 \mu 1$ of $29 \%$ ammonium hydroxide reagent (supplied by Sigma-Aldrich, Germany) was applied with exposure of $10 \mathrm{~min}$. This step was repeated after 7 day incubation on the next set of Petri dishes.

\section{Coconut Milk Agar (CMA)}

The CMA was prepared from $400 \mathrm{ml}$ coconut milk in the tin $(60 \%$ coconut, Alnatura, Germany). The tin was heated in a water bath at $48{ }^{\circ} \mathrm{C}$, coconut milk was centrifuged at $18.063 \mathrm{~g}$ for 8 min, coconut fat was removed and the homogenate was filtered. The clear filtrate was adjusted by $2 \mathrm{~N}$ sodium hydroxide to $\mathrm{pH} 7.0 \pm$ 0.2 . Bacteriological agar $\left(15 \mathrm{~g} \cdot \mathrm{l}^{-1}\right)$ was added to the filtrate and the final medium was sterilized by autoclaving. A total of 14 Petri dishes were prepared of $400 \mathrm{ml}$ of coconut milk. The CMA was inoculated by the toxigenic strain of A. flavus CCF 139, A. carbonarius ITEM 5010, and Penicillium citrinum CCF 1812 and incubated at $30{ }^{\circ} \mathrm{C}$ for 3 days.

\section{Creatine Saccharose Agar (CSA)}

The CSA consists of many components. One of them was prepared from a mineral solution, which consisted of $5 \mathrm{~g}$ of potassium chloride, $5 \mathrm{~g}$ of magnesium sulphate, and $0.1 \mathrm{~g}$ of ferrous sulphate which were dissolved in $100 \mathrm{ml}$ of distilled water. Copper-zinc concentrate was also prepared from $1 \mathrm{~g}$ of zinc sulphate and $0.5 \mathrm{~g}$ of copper sulphate dissolved in $100 \mathrm{ml}$ of distilled water. For the preparation of CSA, $10 \mathrm{ml}$ of prepared mineral solution were mixed with $1 \mathrm{ml}$ of prepared copper-zinc concentrate, $3 \mathrm{~g}$ of creatine, $30 \mathrm{~g}$ of saccharose, $1.3 \mathrm{~g}$ of dipotassium hydrogen phosphate, $0.05 \mathrm{~g}$ of bromine cresol purple and $15 \mathrm{~g}$ of bacteriological agar per 1,000 ml of distilled water. The CSA was sterilized by autoclaving and poured into the sterile Petri dishes under aseptic conditions. On the agar, the toxigenic strain of $P$. expansum NRC P-27/2-14 was inoculated and incubated at 25 ${ }^{\circ} \mathrm{C}$ for 3-5 days.

\section{Chloramphenicol Glucose Yeast Extract (CGYE)}

Distilled water $(500 \mathrm{ml})$ was added to the $18.55 \mathrm{~g}$ of glucose yeast extract agar (supplied by HiMedia, India). After autoclaving, one vial of Chloramphenicol Selective Supplement (SR0078E, supplied by Oxoid, England) reconstituted by instruction was added. The prepared medium was poured into sterile Petri dishes under aseptic conditions. On the medium, the toxigenic strain of $A$. carbonarius ITEM 5010 was inoculated and incubated at $25{ }^{\circ} \mathrm{C}$ for $2-3$ days.

\section{Dichloran Rose Bengal Yeast Extract Sucrose Agar (DRYES)}

The DRYES agar was prepared at our laboratory from $20 \mathrm{~g}$ of yeast extract, $150 \mathrm{~g}$ of sucrose, $1.0 \mathrm{ml}$ of dichloran $(0.2 \%$ in ethanol), $0.5 \mathrm{ml}$ of Rose bengal ( $5 \%$ solution), $0.1 \mathrm{~g}$ of chloramphenicol and $20 \mathrm{~g}$ of bacteriological agar. The components were dissolved in $1,000 \mathrm{ml}$ of distilled water. The final medium was sterilized by autoclaving and poured into sterile Petri dishes under aseptic conditions. On the agar, the toxigenic strain of Penicillium verrucosum CCF 1636 was inoculated and incubated at $25^{\circ} \mathrm{C}$ for $2-3$ days.

\section{Ehrlich's Aldehyde Test (EAT)}

The Ehrlich's reagent was prepared by $1 \%$-dimethylamino-benzaldehyde in $75 \mathrm{ml}$ of ethanol and $25 \mathrm{ml}$ of $\mathrm{HCl}$ concentrate. An agar plug $(5 \mathrm{~mm})$ was cut off from the centre of A. flavus CCF 139 and A. flavus $\mathrm{NRC}$ M-63-11 colony grown on YES agar at $30{ }^{\circ} \mathrm{C}$ for 7 days. The agar plug was placed with the mycelial side on a filter paper sodden by Ehrlich's reagent. The agar plug was removed and a drop of Ehrlich's reagent was applied on the filter paper. The reaction was visible after 2-6 min.

\section{Medium for cultivation of Aspergillus ochraceus (6 MFA)}

The amount of $70.0 \mathrm{~g}$ of 6 MFA (supplied by HiMedia, India) was completely dissolved in 1,000 ml distilled water. The suspension was sterilized by autoclaving and poured into sterile Petri dishes under aseptic conditions. The 6 MFA were inoculated with the toxigenic strain of $A$. ochraceus CCM F-269 and incubated at $25^{\circ} \mathrm{C}$ for $3-5$ days. The toxigenic strain was inoculated also on the MEA and incubated at $25^{\circ} \mathrm{C}$ for 7 days. 


\section{Results and Discussion}

In this study, chromogenic media were used for detection of the toxigenic strains isolated from foodstuffs.

ADMB agar was used for detection of Aspergillus flavus produced by aflatoxins. Results of tests on the ADMB agar showed that the toxigenic strain of A. flavus CCF 139 produced aflatoxins to form intense bright orange-yellow colour on the reverse side colonies after 3 day incubation at $30{ }^{\circ} \mathrm{C}$ (Plate XI, Fig. 1). The study of Bothast and Fennell (1974) explained that ferric ions are necessary in order to form an orange-yellow complex on the reverse side colonies. Then, a few years later Assante et al. (1981) reported in more detail that orange-yellow colouration is caused by the reaction of ferric ammonium citrate with aspergillic acid resulting in a coloured complex. Bothast and Fennell (1974) developed the medium called Aspergillus Differential Medium (ADM) for the identification of aflatoxins produced by $A$. flavus and closely related species with incubation at $28{ }^{\circ} \mathrm{C}$ for 3 days. The composition of this medium was refined by Pitt et al. (1983) with incubation at $30{ }^{\circ} \mathrm{C}$ for 2 days. Pitt et al. (1983) also refined the formula for the media AFPA for detection of $A$. flavus and A. parasiticus produced by aflatoxins. Tested toxigenic strain of $A$. flavus CCF 139 on the AFPA produced aflatoxins to form the intense bright orangeyellow colour on the reverse side colonies at $30^{\circ} \mathrm{C}$ for 2 day incubation (Plate XI, Fig. 2).

Ammonium hydroxide reagent was used to detect aflatoxins produced by $A$. flavus. The ammonium hydroxide was applied on the lid of Petri dish with toxigenic strain of $A$. flavus NRC M-63-11 after 3 and 7 days incubation on YES agar at $30{ }^{\circ} \mathrm{C}$. The vapours of this reagent changed the colour of the surface of the colonies after a 10-min exposure. The surface of colonies was changed to pink colouration that was characterized as moderately toxigenic (Plate XI, Fig. 3). This reagent with non-toxigenic strains does not change colour of the A. flavus colony. Ammonium hydroxide reagent is useful for approximate diagnostics of aflatoxins and it was performed according to Saito and Machida (1999). In our study, this chemical reaction was more visible on the series of Petri dishes after incubation for 3 days and categorized by Kumar et al. (2007).

The CMA was primarily used for the detection of aflatoxins produced by A. flavus. The toxigenic strains of $A$. flavus CCF 139, A. carbonarius ITEM 5010 and Penicillium citrinum CCF 1812 were placed under a UV lamp $(\lambda=365 \mathrm{~nm})$. On the tested toxigenic strain of A. flavus CCF 139 we observed moderately blue fluorescent ring surrounding the colony (Plate XI, Fig. 4). On the tested toxigenic strain of $A$. carbonarius ITEM 5010 produced by ochratoxin A we observed highly blue-green fluorescent ring (Plate XII, Fig. 5). On the other hand, the tested strain of $P$. citrinum CCF 1812 was highly positive on the CMA, producing an intense green-yellow fluorescent ring (Plate XII, Fig. 6). It has been shown that the toxigenic strain of A. flavus was detected on the CMA by weak blue fluorescent ring. We also tested the toxigenic strain of $A$. carbonarius on the CMA which was performed according to the directions by Heenan et al. (1998). The colouration of the $P$. citrinum strain may be characteristic of citrinin production which is mentioned in a study of Mohamed et al. (2013).

The CSA was used as a diagnostic medium in Penicillium taxonomy, namely for diagnostics of Penicillium expansum. The toxigenic strain of $P$. expansum NRC P-27/214 changed the colour of the CSA after incubation from violet to yellow zone around the colonies (Plate XII, Fig. 7). This diagnostic medium described by Frisvad (1985) was modified using various the amounts of creatine and sucrose, wide $\mathrm{pH}$ range (especially at pH 6 or 9) or different carbon/nitrogen ratio (Frisvad 1993). The CSA has a potential to be a very useful taxonomic medium for the species Penicillium subgenus Penicillium (Pitt 1993). This medium is useful for detecting the strain of Penicillium among a large amount of foodstuff and feedstuff samples. 
The CGYE medium was prepared in our laboratory and used for the detection of $A$. carbonarius. The tested strain of $A$. carbonarius ITEM 5010 produced by ochratoxin A was proven on the CGYE agar in a form of colonies with blue colouration on the reverse side (Plate XII, Fig. 8). The basic composition of CGYE was originally formulated by Mossel et al. (1970). In their study, they used Oxytetracycline Glucose Yeast Extract (OGYE) agar for the selective enumeration of moulds in foods which was suggested by Mossel et al. (1962). In our laboratory, we prepared glucose yeast extract agar with chloramphenicol. This medium is only for approximate detection.

In this study, the DRYES agar was prepared to detect $P$. verrucosum producing ochratoxin A (Lund and Frisvad 2003). On the DRYES agar the toxigenic strain of $P$. verrucosum CCF 1636 produced a dark purple colour on the reverse side of colonies after incubation for 3 days at $25^{\circ} \mathrm{C}$ (Plate XIII, Fig. 9). Frisvad (1983) found that $P$. verrucosum had a violet brown or reddish brown colour on the reverse side of colonies upon the YES agar. Based on this fact, DRYES was developed as an indicative and selective medium for the detection of $P$. verrucosum.

Ehrlich's test was used for the detection of A. flavus producing cyclopiazonic acid. The cyclopiazonic acid produced by strain of the A. flavus CCF 139 reacted with Ehrlich's reagent to produce a blue violet ring on the filter paper during the first $6 \mathrm{~min}$. In the next minutes, the blue violet ring quickly started to disappear (Plate XIII, Fig. 10). The strain of $A$. flavus NRC M-63-11 reacted with Ehrlich's reagent to produce a very weakly blue violet ring on the filter paper. This filter paper method was developed by Lund (1995). The positive colour reaction is caused by the indole secondary metabolites produced by moulds reacting with the Ehrlich's reagent (Samson et al. 2007). It is therefore possible that the strain of $A$. flavus NRC M-63-11 did not produce sufficient amount of cyclopiazonic acid to produce a stable colour reaction. The results of this test are obtained very fast but they are only approximate.

The toxigenic the strain of $A$. ochraceus CCM F-269 producing ochratoxins was tested on the 6 MFA. After cultivation the tested strain grew on the 6 MFA with white to creamy white coloured colonies, and on the reverse side, bright yellow colonies (Plate XIII, Fig. 11). Aspergillus ochraceus was compared with colonies grown on the MEA which had a brown colouration on the both sides of colonies (Pitt 1994).

In conclusion, the aim of this study was to experimentally test culture media and reagents for a rapid diagnosis of toxigenic microfungi isolated from foodstuffs. These rapid diagnostic tests are useful for a laboratory with basic equipment for microbiological and mycological analysis. In addition to the easy availability and relatively low prices, another advantage of chromogenic media is the rapid diagnosis taking only $48-72 \mathrm{~h}$, although it presents just a screening test. The toxigenicity of microfungi must be then confirmed by chromatographic methods (e.g., HPLC, LC-MS/MS) and/or molecular biological methods (e.g., PCR, RT-PCR).

\section{Acknowledgements}

This study was supported by the Ministry of Health, Czech Republic - conceptual development of the research organization ('National Institute of Public Health - NIPH, IN 75010330') and by institutional research of the Faculty of Science ('Programme in Biology and Chemistry'), University in Hradec Králové, Czech Republic.

\section{References}

Assante G, Camarda L, Locci R, Merlini L, Nasini G, Papadopoulos E 1981: Isolation and structure of red pigments from Aspergillus flavus and related species, grown on a differential medium. J Agric Food Chem 29: 785-787

Bothast RJ, Fennell DI 1974: A medium for rapid identification and enumeration of Aspergillus flavus and related organisms. Mycologia 66: 365-369 
Frisvad JC 1983: A selective and indicative medium for groups of Penicillium viridicatum producing different mycotoxins in cereals. J Appl Bacteriol 54: 409-416

Frisvad JC 1985: Creatine sucrose agar, a differential medium for mycotoxin producing terverticillate Penicillium species. Let Appl Microbiol 1: 109-113

Frisvad JC 1993: Modifications on media based on creatine for use in Penicillium and Aspergillus taxonomy. Let Appl Microbiol 16: 154-157

Heenan CN, Shaw KJ, Pitt JI 1998: Ochratoxin A production by Aspergillus carbonarius and A. niger isolates and detection using coconut cream agar. J Food Mycol 1: 67-72

Klich MA 2007: Aspergillus flavus: the major producer of aflatoxin. Mol Plant Pathol 8: 713-722

Kumar S, Shekhar M, Ali KA, Sharma P 2007: A rapid technique for detection of toxigenic and non-toxigenic strain of Aspergillus flavus from maize grain. Ind Phytopathol 1: 31-34

Lund F, Frisvad JC 2003: Penicillium verrucosum in wheat and barley indicates presence of ochratoxin A. J Appl Microbiol 95: 1117-1123

Lund F 1995: Differentiating Penicillium species by detection of indole metabolites using a filter paper method. Let Appl Microbiol 20: 228-231

Mohamed S, Flint S, Palmer J, Fletcher GC, Pitt JI 2013: An extension of the coconut cream agar method to screen Penicillium citrinum isolates for citrinin production. Let Appl Microbiol 57: 214-219

Mossel DAA, Kleynen-Semmeling AMC, Vincentie HM, Beerens H, Catsaras M 1970: Oxytetracycline-glucoseyeast extract agar for selective enumeration of moulds and yeasts in foods and clinical material. $\mathrm{J}$ Appl Bacteriol 33: 454-457

Mossel DAA, Visser M, Mengerink WHJ 1962: A comparison of media for the enumeration of moulds and yeasts in foods and beverages. Lab Practice 11: 109-112

Ostry V, Malir F, Ruprich J 2013: Producers and important dietary sources of ochratoxin A and citrinin. Toxins 5: $1574-1586$

Pitt JI 2002: Biology and ecology of toxigenic Penicillium species. Adv Exp Med Biol 504: 29-41

Pitt JI, Hocking AD, Glenn DR 1983: An improved medium for the detection of Aspergillus flavus and A. parasiticus. J Appl Bacteriol 54: 109-114

Pitt JI 1993: A modified creatine sucrose medium for differentiation of species in Penicillium subgenus Penicillium. J Appl Bacteriol 75: 559-563

Pitt JI 1994: The current role of Aspergillus and Penicillium in human and animal health. J Med Vet Mycol 32: 17-32

Pitt JI 2000: Toxigenic fungi and mycotoxins. British medical bulletin 56: 184-192

Ramírez-Camejo LA, Zuluaga-Montero A, Lázaro-Escudero MA, Hernández-Kendall VN, Bayman P 2012: Phylogeography of the cosmopolitan fungus Aspergillus flavus: Is everything everywhere? Fungal Biol 116: 452-463

Saito M, Machida S 1999: A rapid identification method for aflatoxin producing strains of Aspergillus flavus and A. parasiticus by ammonia vapor. Mycoscience 40: 205-208

Samson RA, Noonim P, Meijer M, Houbraken J, Frisvad JC, Varga J 2007: Diagnostic tools to identify black aspergilli. Stud Mycol 59: 129-145

Varga J, Rigó K, Tóth B, Téren J, Kozakiewicz Z 2003: Evolutionary relationships among Aspergillus species producing economically important mycotoxins. Food Technol Biotechnol 41: 29-36

Wu F 2015: Global impacts of aflatoxin in maize: trade and human health. World Mycotoxin Journal 8: 137-142 
Plate XI

Jefremova M. et al.: Rapid diagnostic ... pp. 151-156

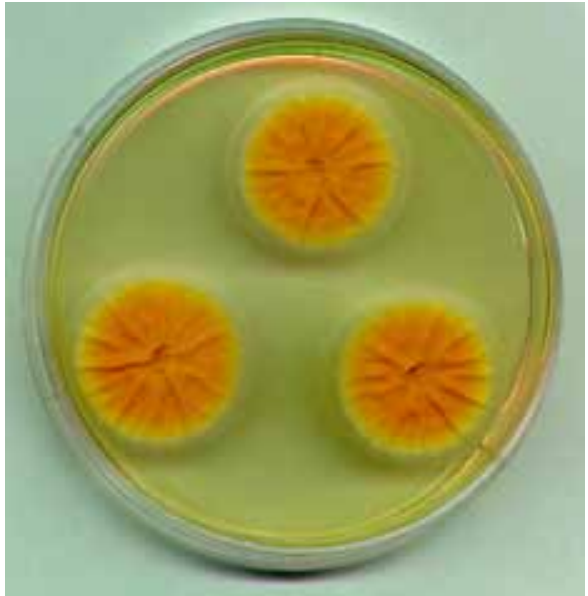

Fig. 1. The strain of Aspergillus flavus CCF 139 on the Aspergillus Differentiation Medium Base agar on the reverse side of colonies

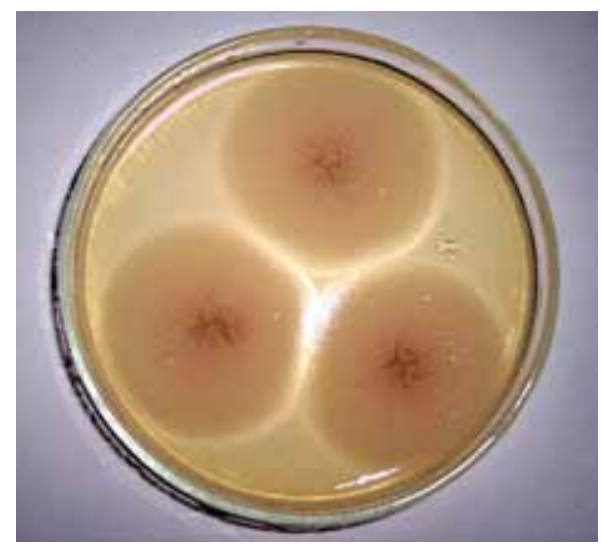

Fig. 3. The strain of Aspergillus flavus NRC M-6311 on the Yeast Extract Sucrose agar after applying ammonium hydroxide reagent

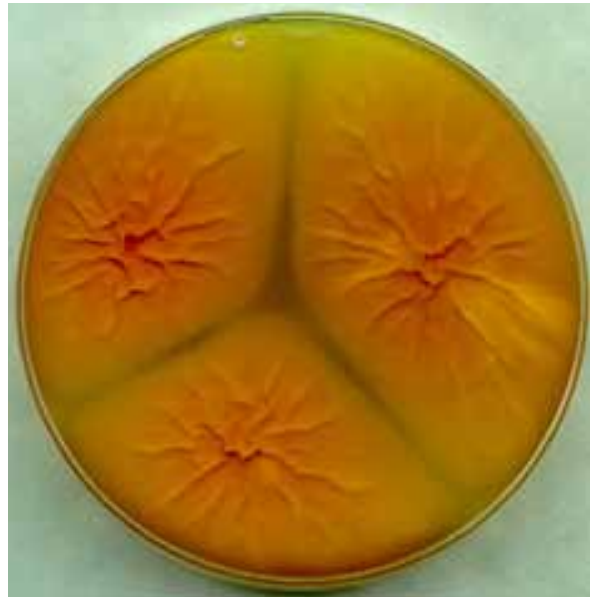

Fig. 2. The strain of Aspergillus flavus CCF 139 on the Aspergillus flavus and parasiticus Agar on the reverse side of colonies

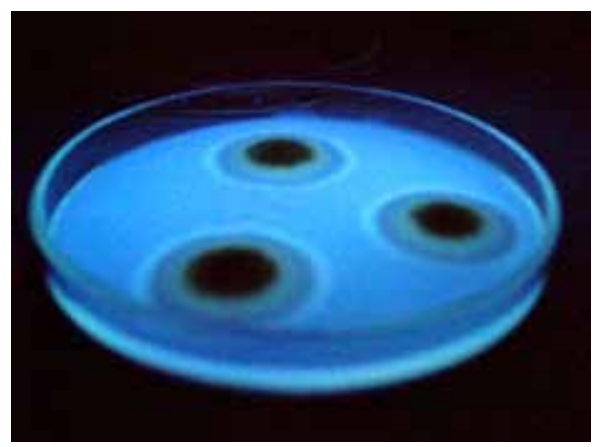

Fig. 4. The strain of Aspergillus flavus CCF 139 on the Coconut Milk Agar under a UV lamp 


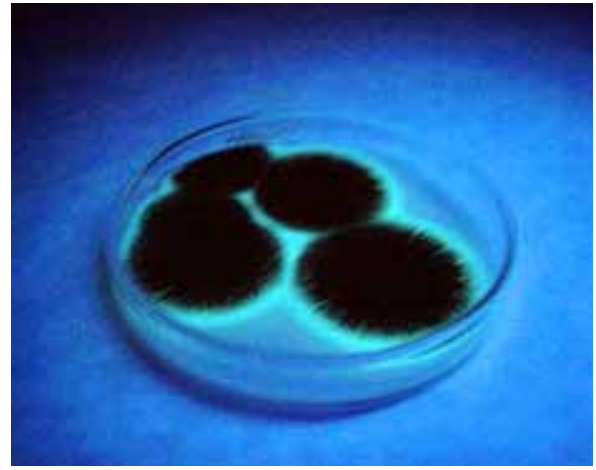

Fig. 5. The strain of Aspergillus carbonarius ITEM 5010 on the Coconut Milk Agar under a UV lamp

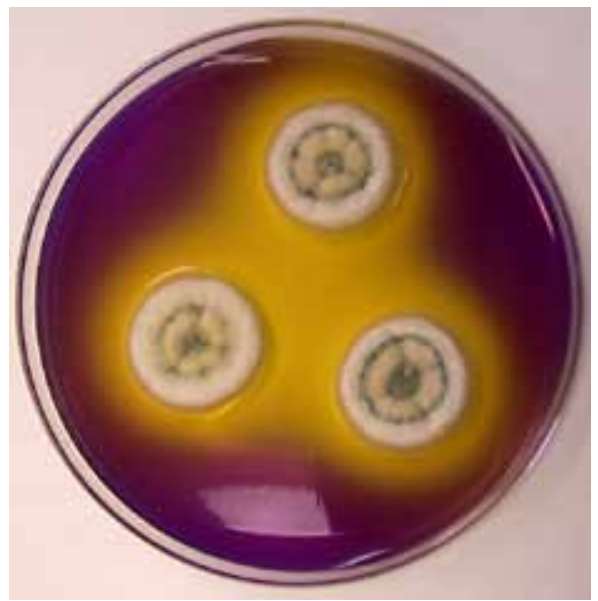

Fig. 7. The strain of Penicillium expansum NRC P-27/2-14 on the Creatine Saccharose Agar

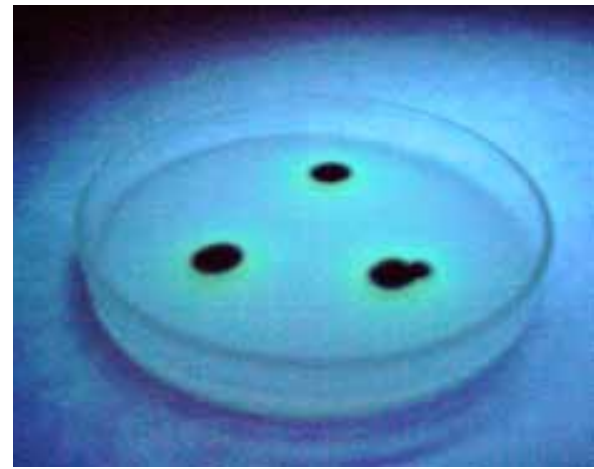

Fig. 6. The strain of Penicillium citrinum CCF 1812 on the Coconut Milk Agar under a UV lamp

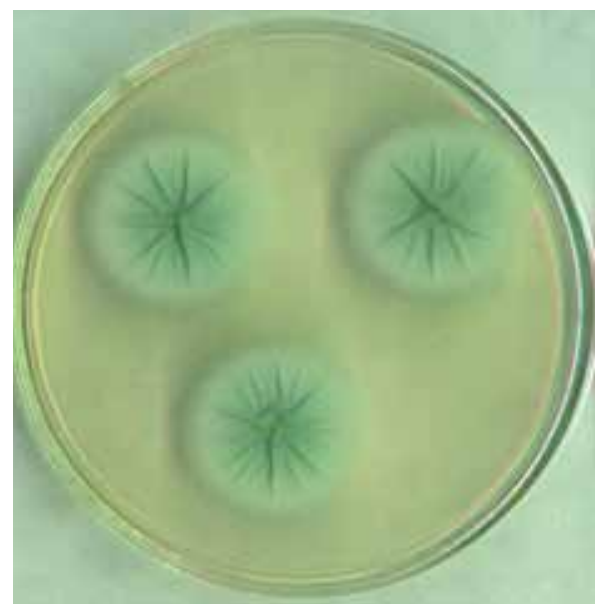

Fig. 8. The strain of Aspergillus carbonarius ITEM 5010 on the Chloramphenicol Glucose Yeast Extract agar on the reverse side of colonies 
Plate XIII
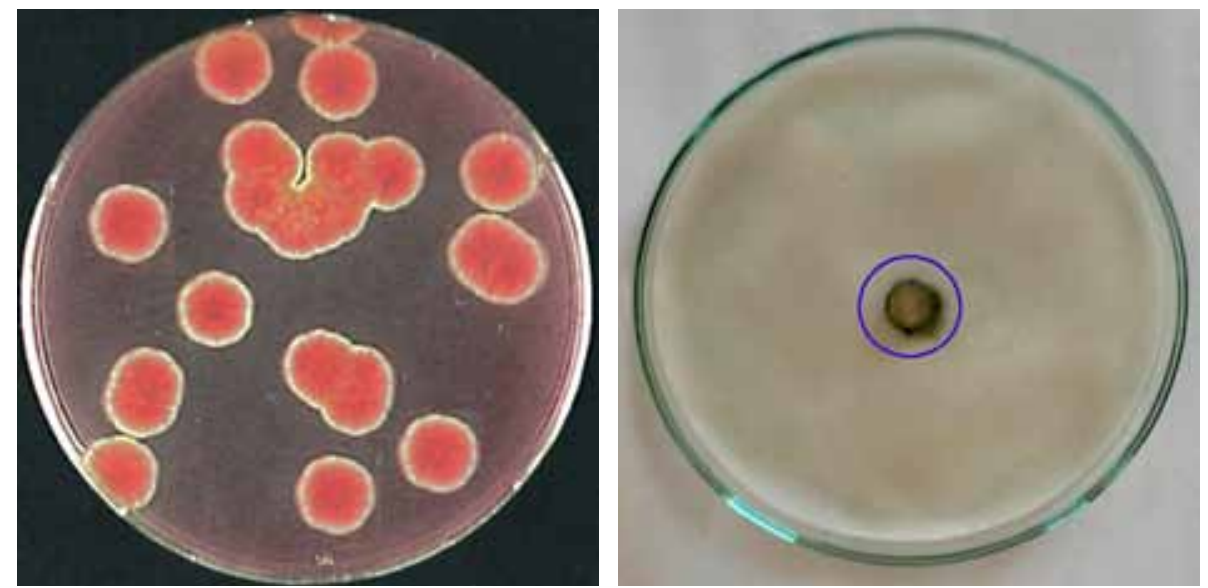

Fig. 9. The strain of Penicillium verrucosum CCF Fig. 10. The strain of Aspergillus flavus CCF 139 on 1636 on the Dichloran Rose Bengal Yeast Extract the filter paper after applying Ehrlich's reagent Sucrose Agar on the reverse side of colonies

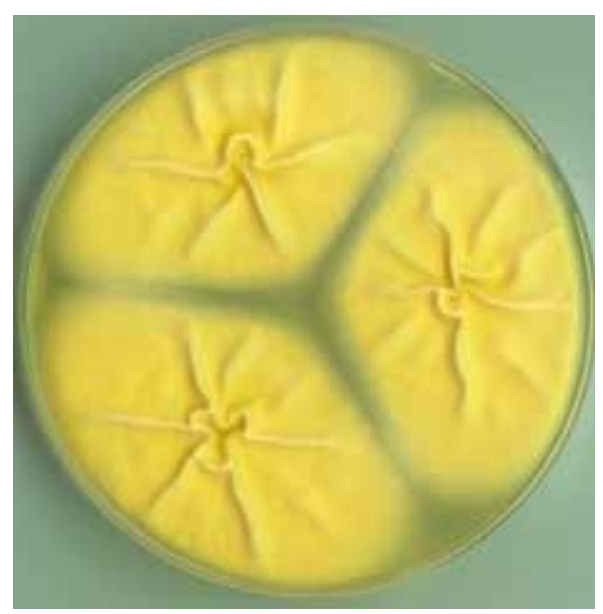

Fig. 11. The strain of Aspergillus ochraceus CCM F-269 on the Medium for cultivation of Aspergillus ochraceus on the reverse side of colonies 